\title{
Autoclaved Aerated Concrete Block Prefabricated Multi-Storey Building Technology
}

\author{
Jingjing Sun* \\ Chongqing Energy Vocational College, Chongqing 402260, China \\ *Corresponding author: Jingjing Sun, jiangwei001vip@126.com
}

Copyright: ( $) 2022$ Author(s). This is an open-access article distributed under the terms of the Creative Commons Attribution License (CC BY 4.0), permitting distribution and reproduction in any medium, provided the original work is cited.

\begin{abstract}
In active response to the national requirements of promoting green building materials and developing prefabricated buildings, it is necessary to continuously optimize and reasonably employ relevant technologies. Autoclaved aerated concrete block prefabricated multi-storey building technology is a new technology, which will not only effectively realize green environmental protection in construction engineering, but also promote the further development of prefabricated buildings. Therefore, this paper analyzes the autoclaved aerated concrete block prefabricated multi-storey building technology for future references.
\end{abstract}

Keywords: Autoclaved aerated concrete; Building block; Prefabricated building; Multi-storey building

Online publication: March 4, 2022

\section{Introduction}

Prefabricated building is a type of building in which its building components are produced first and then assembled on the construction site. Autoclaved aerated concrete block prefabricated multi-storey building is one of the changes in prefabricated buildings, which can effectively save energy and resources, reduce construction pollution, and improve production efficiency as well as the safety level. At the same time, strengthening the integration between the production process and informatization along with industrialization is conducive to cultivating new drivers for new industries and improving overcapacity. In the past, autoclaved aerated concrete blocks have been used to build walls, but they are rarely used directly in building construction. In order to effectively promote the concepts of openness, sharing, green, and innovation, autoclaved aerated concrete blocks have been optimized and ensured that they adhere to standardized design, production, construction, and decoration, so as to promote the transformation and upgrading of the construction industry. Based on this, it is of great significance to analyze the autoclaved aerated concrete block prefabricated multi-storey building technology.

\section{Definition of autoclaved aerated concrete block prefabricated building}

Autoclaved aerated concrete block prefabricated building refers to a residence built in the form of industrial production; the wall limbs, roof panels, floors, and stairs are manufactured in the factory, and transported to the construction site; they components are then connected to form a building.

\section{Application situation of autoclaved aerated concrete block prefabricated building technology}

Modern countries attach great importance to urbanization and the construction of "new countryside." In view of the actual situation, they have launched many favorable policies that can promote urbanization and 
the development of "new countryside," thus improving the living standards of urban and rural residents. However, for residential buildings in urban and rural areas, there are cases with low scientific and technological content, short service life, poor construction quality, and low cost performance. The reason for this situation is that advanced technology and high-quality materials are not applied in the construction process, and there are no available professional personnel to give corresponding guidance. In addition, the substandard quality of the construction team also contributes to this situation to a certain extent. In order to effectively improve the adverse situation, it is necessary to apply advanced technology and use high-quality materials in the construction process, employ highly professional staffs to carry out the construction work, and effectively promote as well as apply new products, new technologies, and new materials, so as to significantly improve the housing quality in urban and rural areas.

In line with the aforementioned strategy, applying autoclaved aerated concrete block prefabricated multi-storey building technology to the construction process may be beneficial. However, there are occurrences when the building materials used in the construction process do not conform to the application needs of the building itself. Several conditions, such as the block size does not coordinate with the construction module, the lower limit of the splitting tensile strength does not meet the requirement of the crack in the wall, and the poor water content limit of the outlet kettle is not conducive to the prevention and control work of the shrinkage crack in the wall, will result in the restriction of the application and popularization of advanced technology ${ }^{[1]}$.

In the process of urbanization and the continuous construction of "new countryside" in China, more than 700 million square meters of houses still need to be built every year, in which the mode of industrial production needs to be reasonably applied in this process. Therefore, it is necessary to actively promote the application of autoclaved aerated concrete block prefabricated multi-storey building technology, so that the development progress from block to wall, and to the whole building, thus realizing the development goal of building a multi-storey building.

\section{Reasonable application of autoclaved aerated concrete block prefabricated multi-storey building technology}

Practically speaking, for China's construction industry, the autoclaved aerated concrete block fabricated multi-storey building technology is still a new technology. Many construction teams are still unable to fully grasp the material requirements and design requirements to a certain extent, which is not conducive to the comprehensive application of this technology and does not ensure the safety as well as efficiency of the construction process. Therefore, it is necessary to analyze the reasonable application of this technology as well as clarify the relevant material requirements and design requirements, so as to improve the application effect of this technology in the process of constructing a multi-storey building.

\subsection{Material requirements}

The strength of plates and blocks made of autoclaved aerated concrete should be at least A3.5, the coefficient of variation should be controlled within 0.10 or below, the corresponding split pressure ratio should conform to the "Uniform Technical Code for the Application of Wall Materials," and the height of blocks should be above $240 \mathrm{~mm}$.

Autoclaved aerated concrete reinforced plate should be adopted for floor slab and roof slab, the reinforcement in it should be reinforced with good holding and wrapping force, and the ductility of the reinforcement itself should be adequate.

The thin mortar joint masonry adhesive should be reasonably applied to the mortar, and the wall should be treated in the form of thin plastering. If conditions permit, it is best to use mechanized spraying. In the process of building the autoclaved aerated concrete block exterior wall, the thermal conductivity of the 
special thermal insulation mortar used should be kept at $0.18 \mathrm{w} /(\mathrm{mK})$ or below, so as to ensure that the block would have a good matching thermal performance effect with the mortar, which is conducive to improving the thermal insulation effect of the wall and further optimizing the energy-saving design. Although the thickness of mortar joint should be $10 \mathrm{~mm}$ or less in the design work, the theoretical calculation value can be directly applied in the thermal calculation; that is, the correction coefficient of thermal conductivity and heat storage coefficient does not have to be multiplied by $1.25^{[2]}$. The stairs and other accessories should also be effectively prefabricated.

\subsection{Design requirements}

The design work should be carried out by a special design organization. The personnel involved in the design work are required to be able to effectively apply the relevant knowledge of architectural design and structural design, as well as master the characteristics of autoclaved aerated concrete products, so as to meet the following requirements: (1) design requirements; (2) planning requirements; (3) harmonious environment; (4) comfortable and practical; (5) beautiful personality. In the process of design, the scheme design and preliminary design should be carried out first, followed by the design of construction drawings, wall limb splitting, and block type splitting. At the same time, information data should be transmitted in time with the help of information technology.

Based on the drawings and with the help of Building Information Modeling (BIM) technology, special technical staffs can then split the wall limb. In the splitting process, the size of the wall limb should be based on the size of autoclaved aerated concrete block. At the same time, it is necessary to take into account the wall stress requirements, the number of wall pieces, the performance of walling machine, transportation, and hoisting, as well as other aspects. The shape of reinforcement, structural column, tie beam, and other components may have some impact on it. Therefore, when constructing a series diagram of wall limb, the wall limb should be reasonably divided into different block types using BIM. Different numbers can be used to represent the block types, which can then be counted into a table and uniformly transmitted to the processing section of special-shaped blocks. The processing work can be carried out according to this.

In the construction process, the autoclaved aerated concrete block wall-laying machine should also be used reasonably. This equipment has many functions, such as data identification, automatic setting out, and automatic block setting out. It can also spray the binder automatically and carry out cutting work when necessary. It is very suitable for masonry work ${ }^{[3]}$.

The logistics system should be advanced and maintained professionally. The assembly team is responsible for arranging logistics and transportation equipment to ensure that the transportation of all components is in an ideal state.

As for the construction team on the construction site, they should maintain a high level of professional skills. They should assemble and splice the wall pieces or other components transported to the construction site according to the design and construction requirements in a timely and effective manner.

Autoclaved aerated concrete reinforced slab can be used as floor or roof slab. It is better to use prestressed vierendeel laminated slab. The reason is that this type of slab does not only have the characteristic of high rationality of slab type, but also have superior cost performance and overall strong bearing capacity in view of the high strength prestressed steel rod applied in it. As it has a vierendeel part, water, electricity, heating, and other pipelines can cross it, thus greatly saving the construction space.

A wall panel installation machine can be used to assemble the partition wall of the indoor part. The wall panel installation machine is not only used for wall panel installation, but also serves as a movable construction platform for high-altitude operation, which is conducive to improving the construction efficiency. At present, the wall panel installation machine can be widely used in the installation of wall panels with different structures, in which the application effect is good ${ }^{[4]}$. 
Scientific and reasonable construction standards and methods are important bases for maintaining the safety and effectiveness of the construction process of prefabricated buildings. Therefore, it is necessary to reasonably prepare relevant standards and methods as well as submit them in time for approval. After approval, they should be fully implemented in the construction process.

On the whole, the application of autoclaved aerated concrete block prefabricated multi-storey building technology requires that all masonry walls and components in all aspects should be transported to the construction site first, and the on-site hoisting work should be reasonably carried out with machineries. At the same time, local pouring should be fully cooperated to ensure effective connection of fasteners, so as to complete the construction of multi-storey buildings.

\section{Conclusion}

Autoclaved aerated concrete block prefabricated multi-storey building technology is a new technology vigorously promoted by contemporary departments. It is also the basis for the effective development of the autoclaved aerated concrete market. At the same time, it has grown into an opportunity to effectively change the ideas of building construction. In the application of this technology, it is important to pay attention to meeting the material requirements and design requirements, adopt scientific and reasonable construction measures, as well as use corresponding mechanical equipment to realize the effective construction of prefabricated buildings, which is conducive to improving economic and social benefits.

\section{Disclosure statement}

The author declares no conflict of interest.

\section{References}

[1] Liu X, 2017, Research on Key Technical Issues in the Design and Construction of Autoclaved Aerated Concrete Block Filled Wall. Jiangxi Building Materials, 2017(20): 28.

[2] Yang Y, Wu X, Liang K, 2020, Application of Autoclaved Aerated Concrete Strip in Prefabricated Residential Engineering. Interior Architecture of China, 2020(3): 206-207.

[3] Xiao Z, 2019, Study on Anti-Seismic Performance of RC Frame Structures with Precast AAC Block Filled Walls, Hunan University.

[4] Lu S, Lu T, 2013, Autoclaved Aerated Concrete Short Block, Short Block Combination and Piecework Masonry Method: CN103276844A. 